\title{
TRITIUM MONITORING SYSTEM FOR NEAR AMBIENT MEASUREMENTS ${ }^{1}$
}

\author{
K. G. Falter and M. L. Bauer \\ Instrumentation and Controls Division \\ Oak Ridge National Laboratory \\ P.O. Box 2008, Oak Ridge, Tennessee 37831
}

\begin{abstract}
This paper describes the current status of research on an improved tritium measurement system at the Oak Ridge National Laboratory (ORNL) for the U.S. Navy. Present tritium-in-air monitoring systems installed by the Navy can reliably measure to less than $10 \mu \mathrm{Ci} / \mathrm{m}^{3}$, but medical and safety issues are pushing measurement needs to below $1 \mu \mathrm{Ci} / \mathrm{m}^{3}$, which is equivalent to $1-10 \mathrm{nCi} / \mathrm{ml}$ in liquid samples, using calcium metal converter. A significant effort has been expended over the past 10 years by the Navy RADIAC Development Program at ORNL on various schemes to improve the detection of tritium in both air and liquid at near ambient levels. One such scheme includes a liquid flow-through system based on an NE102 sponge scintillator with dual photomultiplier tubes for tube noise rejection.
\end{abstract}

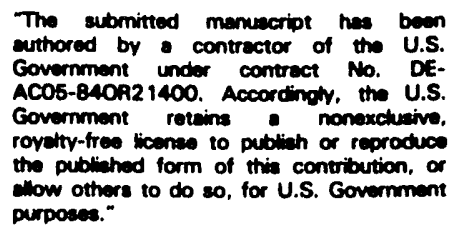

${ }^{1}$ Research sponsored by U.S. Navy RADIAC Development Program under DOE Interagency Agreement 05310531-A1 and performed at Oak Ridge National Laboratory, managed by Martin Marietta Energy Systems, Inc., for the U.S. Department of Energy under contract DE-AC05-84OR21400.

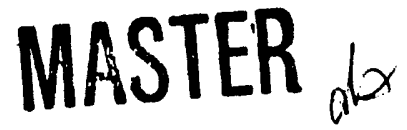




\title{
TRITIUM MONITORING SYSTEM FOR NEAR AMBIENT MEASUREMENTS ${ }^{1}$
}

\author{
K. G. Falter and M. L. Bauer \\ Instrumentation and Controls Division \\ Oak Ridge National Laboratory \\ P.O. Box 2008, Oak Ridge, Tennessee 37831-6006
}

\section{ABSTRACT}

This paper describes the current status of research on an improved tritium measurement system at the Oak Ridge National Laboratory (ORNL) for the U.S. Navy. Present tritium-in-air monitoring systems installed by the Navy can reliably measure to less than $10 \mu \mathrm{Ci} / \mathrm{m}^{3}$, but medical and safety issues are pushing measurement needs to helow $1 \mu \mathrm{Ci} / \mathrm{m}^{3}$, which is equivalent to $1-10 \mathrm{nCi} / \mathrm{ml}$ in liquid samples, using calcium metal converter. A significant effort has been expended over the past 10 years by the Navy RADIAC Development Program at ORNL on various schemes to improve the detection of tritium in both air and liquid at near ambient levels. One such scheme includes a liquid flow-through system based on an NE102 sponge scintillator with dual photomultiplier tubes for tube noise rejection.

\section{INTRODUCTION}

A tritium monitoring system is needed that not only satisfies the low-level sensitivity requirements but also meets the size limitations of shipboard installation. We set out to implement and then improve upon previous work by Singh, et al, of the Bhaba Atomic Research Center, Trombay, India.[1] An improved design for a condensate tritium monitor has been demonstrated using a flowthrough NE102 sponge scintillator combined with dual photomultiplier tubes (PMTs) to form the detector. This tritium monitor utilizes a dual-tube coincidence method to detect very low levels of tritium in water or other aqueous solutions. The flow-through or sampling chamber has a volume of $4.6 \mathrm{cc}$ and contains 5- to 7- $\mu \mathrm{m}$-thick NE102 scintillator packed in the form of a sponge. The photomultiplier tubes are optically coupled to quartz windows, which serve as the walls of the sampling chamber. The close spacing of the chamber walls, shown in Fig. 1, allows the photomultiplier tubes to detect actual scintillations in coincidence while rejecting any stray pulses detected in only one of the PMTs. After obtaining a background reading, measurements were recorded at various sampling intervals

TRescarch sponsored by U.S. Nayy RADIAC Development Program under DOE Interagency Agreement 0531-0531-A1 and performed at Oak Ridge National Laboratory, managed by Martin Marietta Energy Systems, Inc., for the U.S. Department of Energy under contract DE-AC05-84OR21400. using tritiated water concentrations of $0.0258 \mu \mathrm{Ci} / \mathrm{ml}$ and $0.258 \mu \mathrm{Ci} / \mathrm{ml}$. The electronic configuration used for amplification, pulse shaping, and discrimination of the detector signal showed that relatively short sampling times $(\leq 5 \mathrm{~min}$ ) are sufficient for detecting low levels of tritium in water $(\sim 1 \mathrm{nC} / \mathrm{ml})$.

\section{DETECTOR FABRICATION}

The detector was fabricated by dissolving $3 \mathrm{~g}$ of NE102 plastic scintillator in a mixture of $90 \mathrm{ml}$ of ethyl-acetate and $10 \mathrm{ml}$ of amyl-acetate.[2] A 5- to 7- $\mu \mathrm{m}$ film of scintillator is formed when this mixture is poured, in successions of $5 \mathrm{ml}$, into 3 liters of distilled water in a stainless steel tray $30 \mathrm{~cm} \times 30 \mathrm{~cm} \times 4 \mathrm{~cm}$. After 5 minutes, the film can be carefully removed by stretching between two sheets of clean white paper and then allowed to dry in a dust free environment. At this point, the film will have multiple holes of various sizes which will allow water to flow through the scintillator when packed in the sampling chamber. The thin films were precut into circles using a $11 / \mathrm{s}$ inch heavy duty Arch punch. Approximately 300 layers of the film were stacked on top of each other to form a uniform sponge-like scintillator with a surface area of $-1000 \mathrm{~cm}^{2}$. Although the film itself is not permeable to water, the holes in the film allow the sponge to absorb water completely and thus allow a uniform flow through the system.

The mechanical housing for the tritium monitor was constructed of stainless steel, and employed two quartz windows to optically couple the NE102 sponge scintillator to the photomultiplier tubes. The inlet and outlet for the liquid into the sample chamber were $1 / 3$ inch copper tubing epoxied into openings on opposite sides of the housing. The epoxy which attached these tubes to the housing was mixed with carbon black powder to assure light tight connections. The main housing was assembled using $\mathrm{O}$ rings between sections for a water tight fit while spring compression was used on the back of the photomultiplier tubes to hold the tubes tightly against the quartz windows.

\section{OPERATION}

This tritium monitor uses a dual tube coincidence method[3] for detecting very low levels of tritium in water 

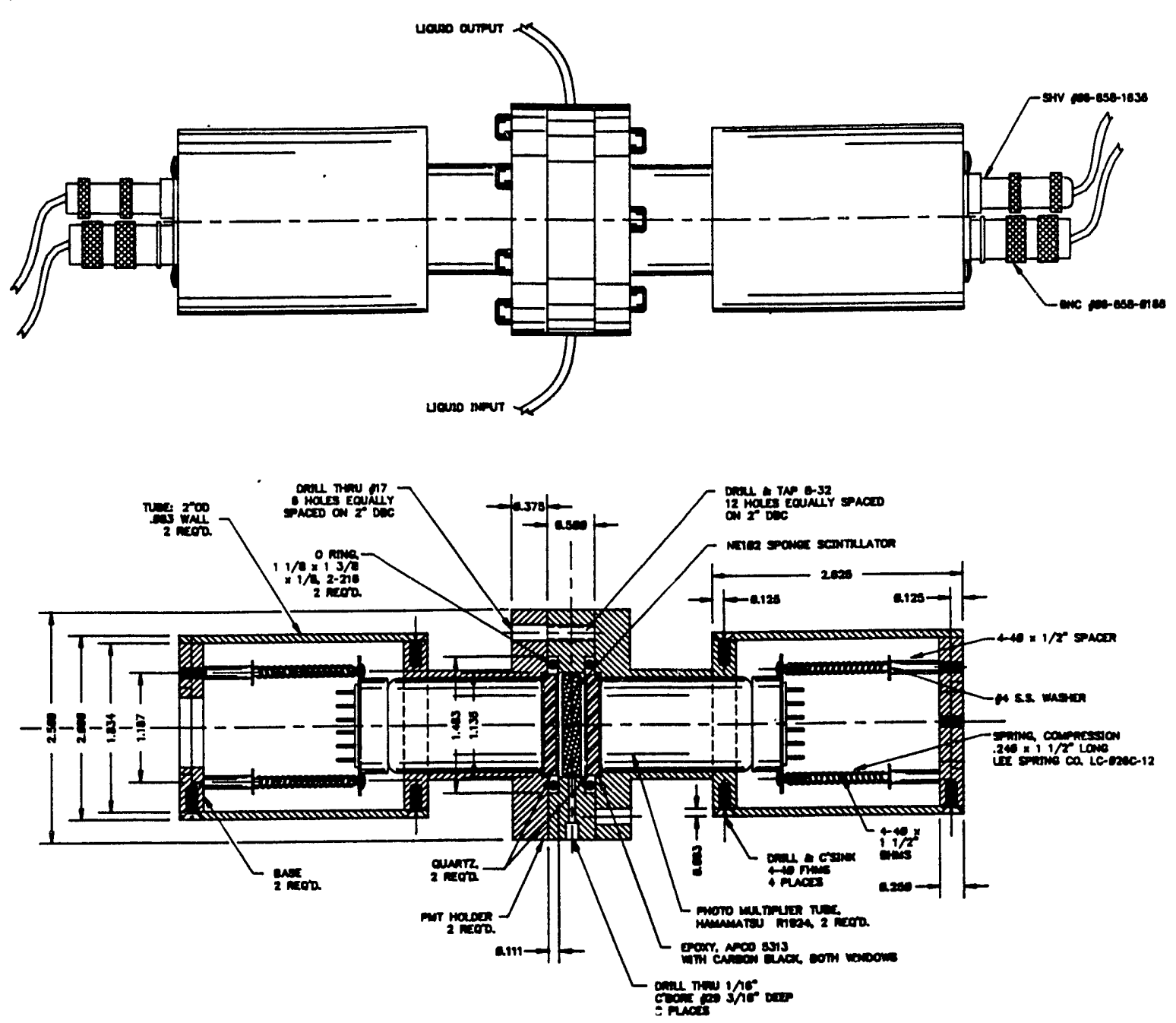

Fig. 1 This is a mechanical drawing of the condensate tritium monitor showing the position of the sponge scintillator with respect to the PMTs.

or other aqueous solutions. The flow-through or sampling chamber has a (free) volume of $4.6 \mathrm{cc}$ and contains the 5-to $7-\mu \mathrm{m}$ thick NE102 scintillator packed in the form of a sponge. The photomultiplier tubes are optically coupled to the quartz windows which comprise the walls of the sampling chamber. The close spacing of the chamber walls allows the photomultiplier tubes to detect actual scintillations in coincidence while rejecting any stray pulses detected in only one of the PMTs. This setup not only yields very low background levels, but also provides good gamma rejection by energy windowing.

Measurements were recorded at $1,2,5,10,15$, and 30 minute sampling intervals using distilled water for a background reading, and different concentrations of tritiated water for the sensitivity measurements. The electronic configuration used for amplification, pulse shaping, and discrimination of the detector's signal is shown in Fig. 2. Using this setup, extremely low background levels $(-40$ cnts/min) were obtained. Only those pulses gated in from the gate generator, which was triggered by the coincidence module, were counted. A resolving time of $0.4 \mu \mathrm{S}$ was selected for optimum efficiency in allowing the two pulses in coincidence to cause a gate pulse to the multichannel analyzer. Fig. 3 shows the output from the multichannel analyzer.

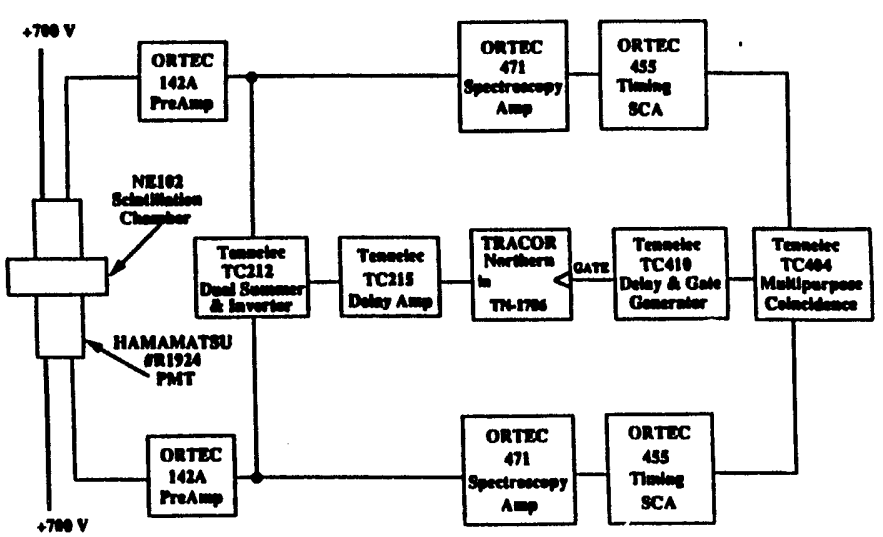

Fig. 2 This shows the electronic configuration with PMT noise rejection. 


\section{MEASUREMENTS}

A solution of tritiated water $2.58 \mu \mathrm{Ci} / \mathrm{ml}$ was diluted into two samples $0.258 \mu \mathrm{Ci} / \mathrm{ml}$ and $0.0258 \mu \mathrm{Ci} / \mathrm{ml}$. These two samples were used in the experiments to determine the sensitivity of this tritium monitor. In order to remove any air trapped in the chamber the solutions were pumped through the detector from bottom to top, using a parastolic pump at a rate of $1 \mathrm{ml} / \mathrm{min}$.

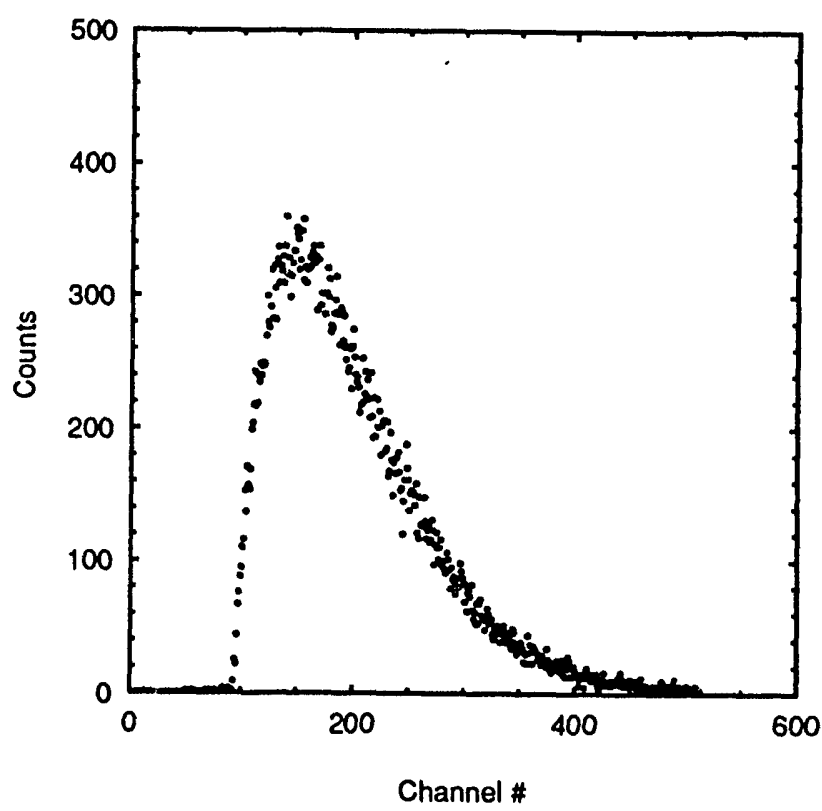

Fig. 3 A typical output as seen on the MCA.

After background measurements were made using pure distilled water, the next step was to run the tritium solutions through for sensitivity measurements. The first tritiated water solution tested was the $0.0258 \mu \mathrm{Ci} / \mathrm{ml} \mathrm{mix}$ ture. Measurements were made for all the time intervals stated previously. After each measurement, distilled water was flowed through the system to try to wash out any tritium residue. The time required to flush out the scintillator was also recorded. The same measurements were done with the $0.258 \mu \mathrm{Ci} / \mathrm{ml}$ solution. Graphs of the actual data, shown in Fig. 4, illustrate that relatively short sampling times ( $\leq 5 \mathrm{~min}$ ) are sufficient for detecting very low levels of tritium in water. These short detection times for such low levels of tritium make this detector quite attractive for medical and safety issues requiring fast response times. These short detection times also help to compensate for the extended lag time, normally several hours, required by scintillation detectors to recover frum tritium memory (or to restore near background levels after the tritiated solution has contaminared the scintiilator). This tritium monitor did not display the long lag times that were expected. Recovery times of 30 minutes and 1 hour were recorded for the $0.0258 \mu \mathrm{Ci} / \mathrm{ml}$ and $0.258 \mu \mathrm{Ci} / \mathrm{ml}$ solutions respectively. Fig. 5 shows the recovery time needed for the condensate tritium monitor to return to background levels.

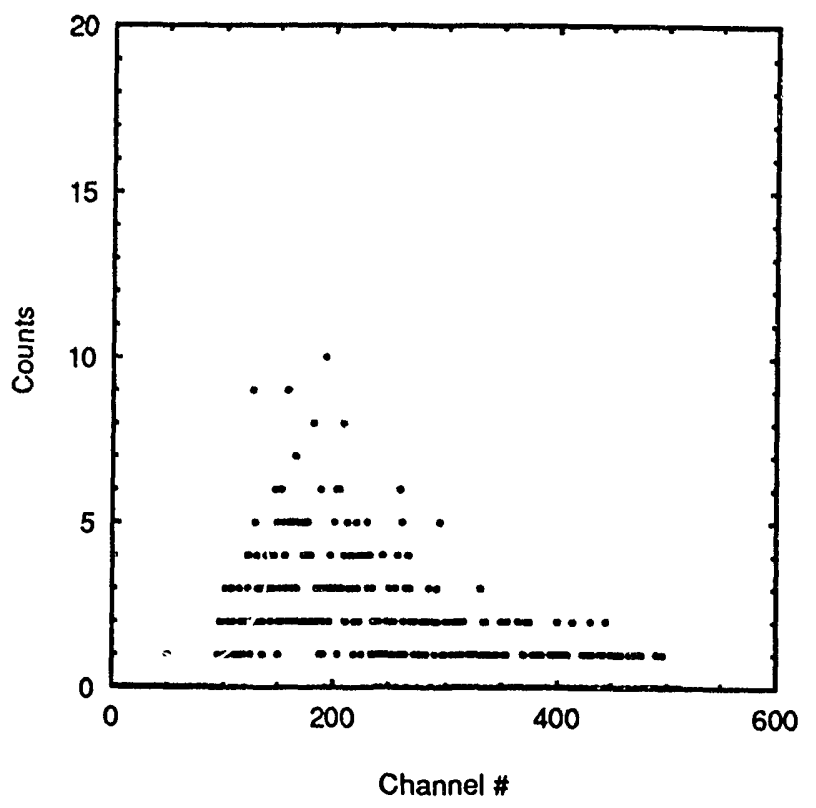

(a)

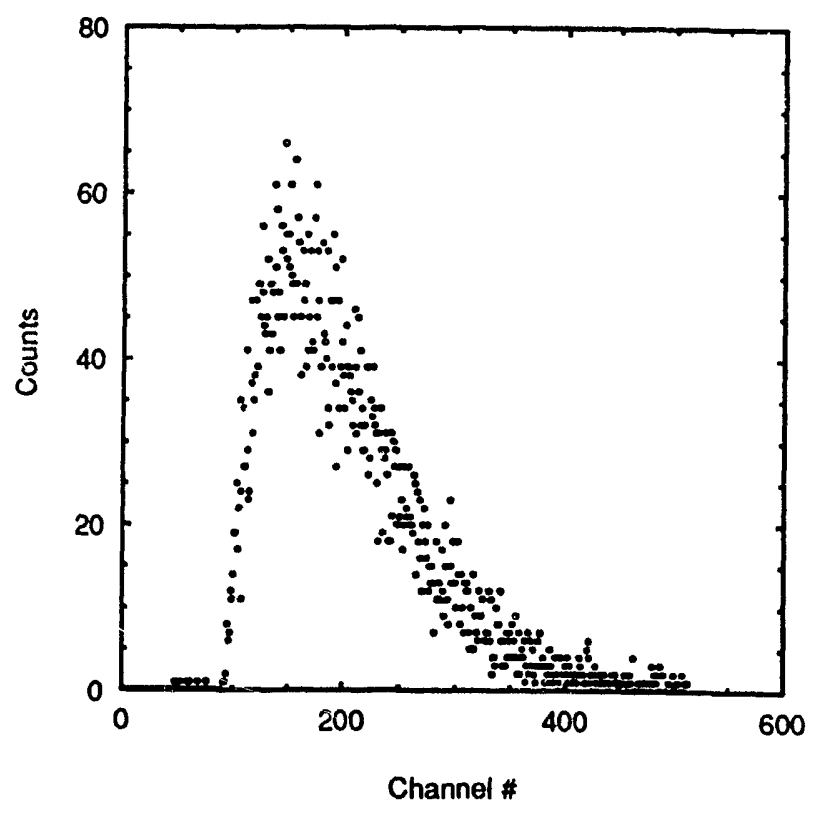

(b)

Fig. 4 Two samples which were run through the condensate tritium monitor for 5 minutes, (a) $0.0258 \mu \mathrm{Ci} / \mathrm{ml}$, (b) $0.258 \mu \mathrm{Ci} / \mathrm{ml}$. 


\section{CONCLUSIONS}

In wnclusion this condensate tritium monitor was calculated to have a sensitivity of approximately $1.0 \mathrm{nCi} / \mathrm{ml}$. This monitor can detect low levels of tritium in much

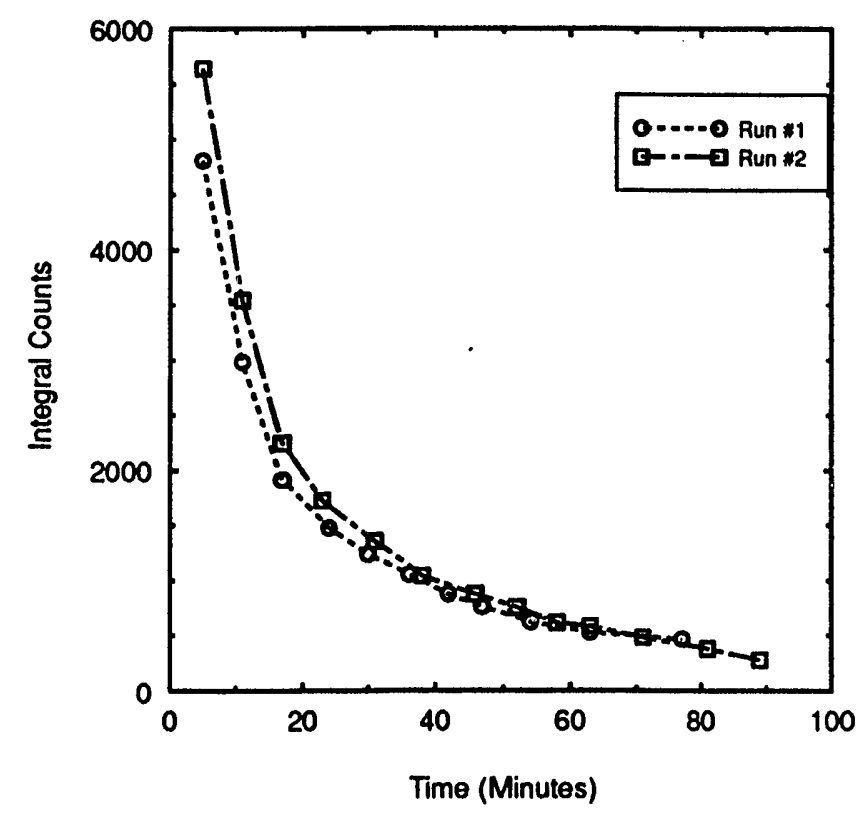

Fig. 5 Graph showing time required for scintillator to recover, after a 5 minute $0.258 \mu \mathrm{Ci} / \mathrm{ml}$ tritium sample had passed through.

shorter time periods than the more common ion chamber based systems, and this shorter detection response time could be very favorable in certain situations. We feel that with the optimization of the current scintillator or through the use of one of the newer aerogel technologies for the scintillator the sensitivity of this detector could be improved up to 2 orders of magnitude. After this work had been completed, we received a copy of more recent work in which Singh, et al, had reported on a similar system with comparable results. [4]

\section{ACKNOWLEDGMENTS}

The authors wish to express their appreciation to the following people who were extremely helpful and supportive throughout this project: V. C. Miller, J. R. Lowery, M. M. Chiles, S. A. McElhaney, K. F. Cutshaw, and C. E. Miles.

\section{REFERENCES}

[1] A. N. Singh, M. Ratnakaran, and K. G. Vohra, "An On-Line Tritium-In-Water Monitor," in Nuclear Instruments and Methods in Physics Research A236 (1985) 159-164, North Holland, Amsterdam.
[2] From method described in above.

[3] M. M. Chiles, "Evaluation of a Thin $\mathrm{CaF}_{2}(\mathrm{Eu})$ Scintillator for Detecting Tritium," in the IEEE Transactions on Nuclear Science, Vol. NS-34, No. 1, February 1987.

[4] A. N. Singh, and M. Rathnakaran, "Development of Continuous Sampling and Monitoring Systems for Tritium in Air and Water," in the Bulletin of Radiation Protection, Vol. 13, No. 1, Jan.-March 1990.

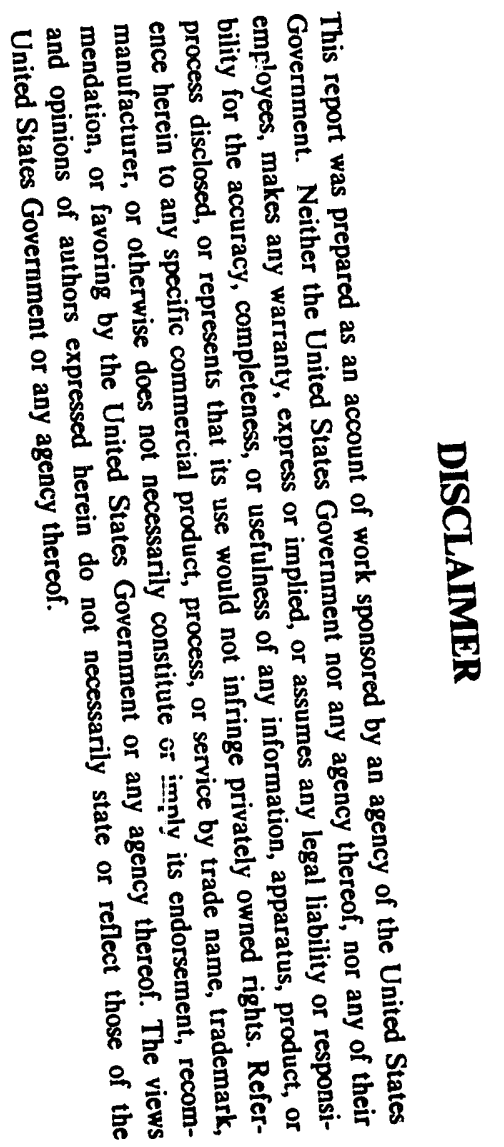




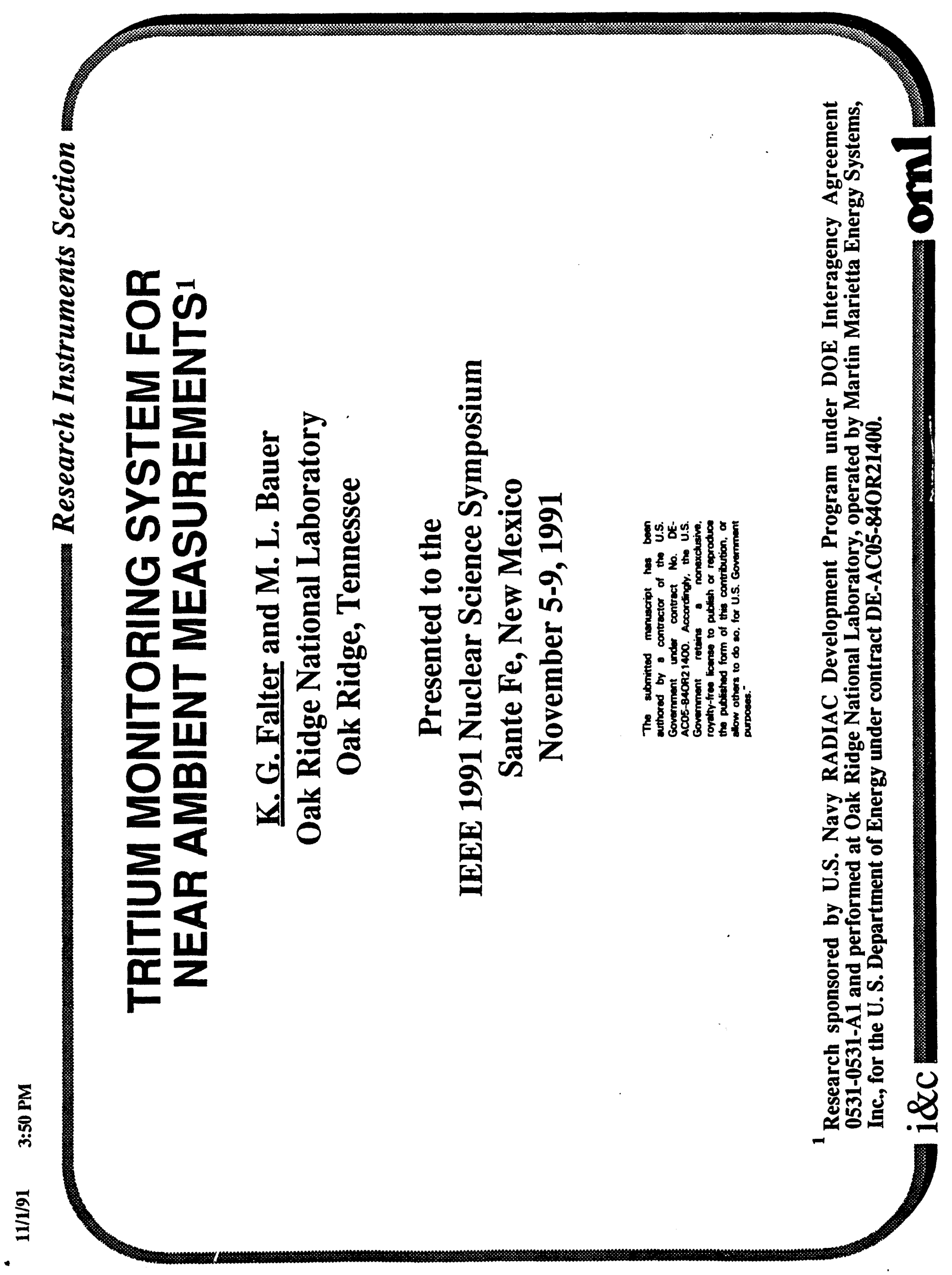




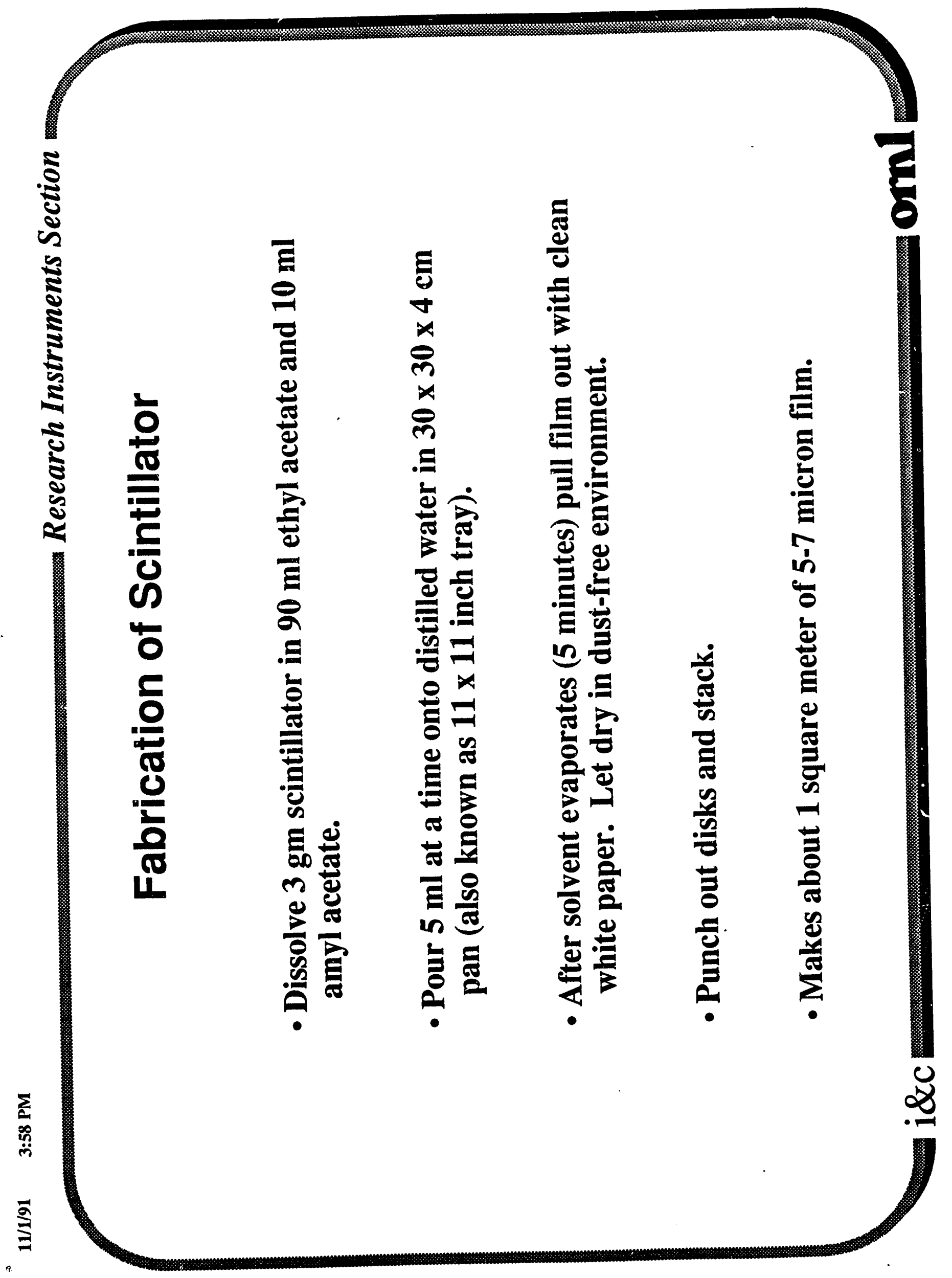




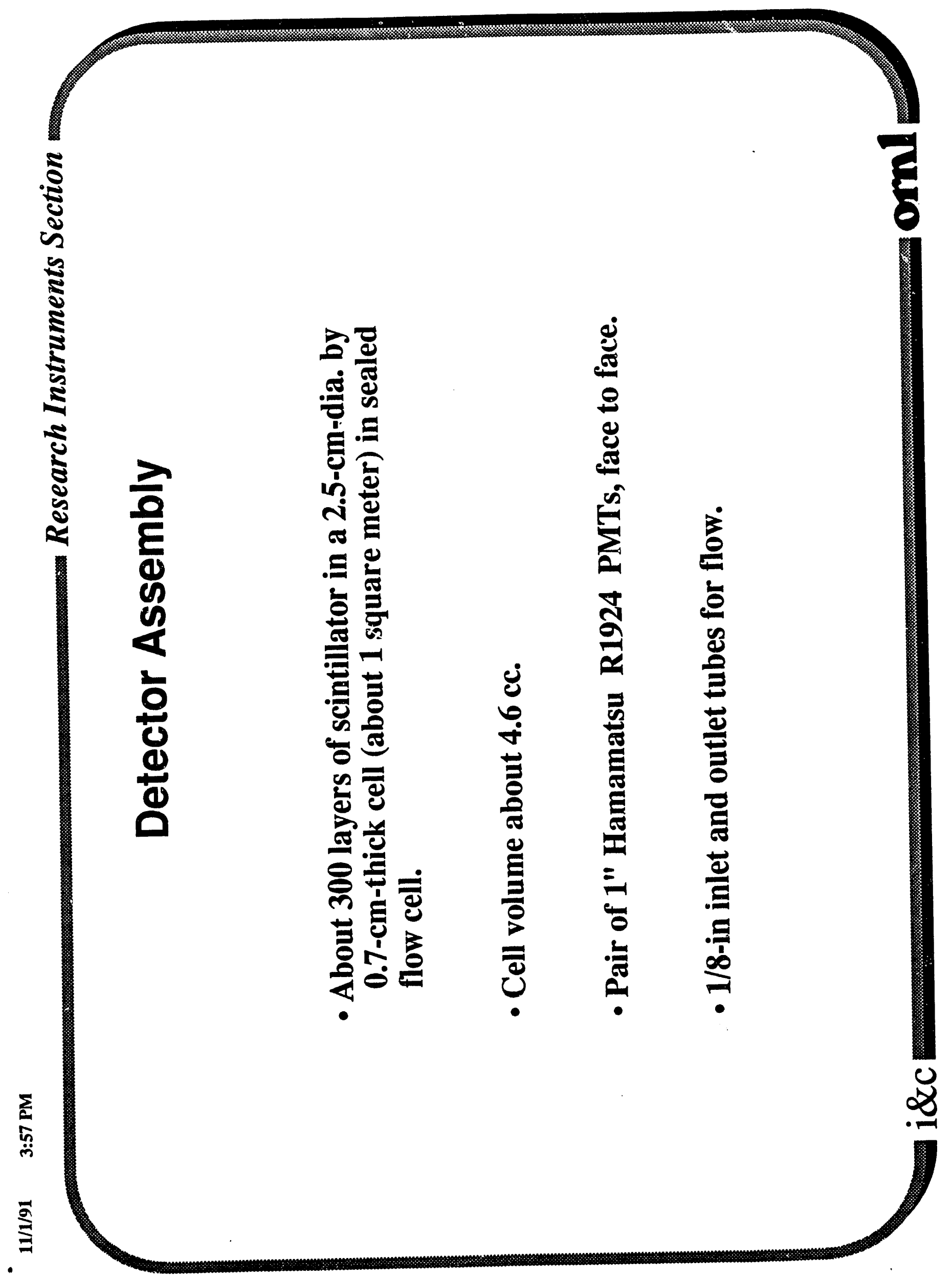




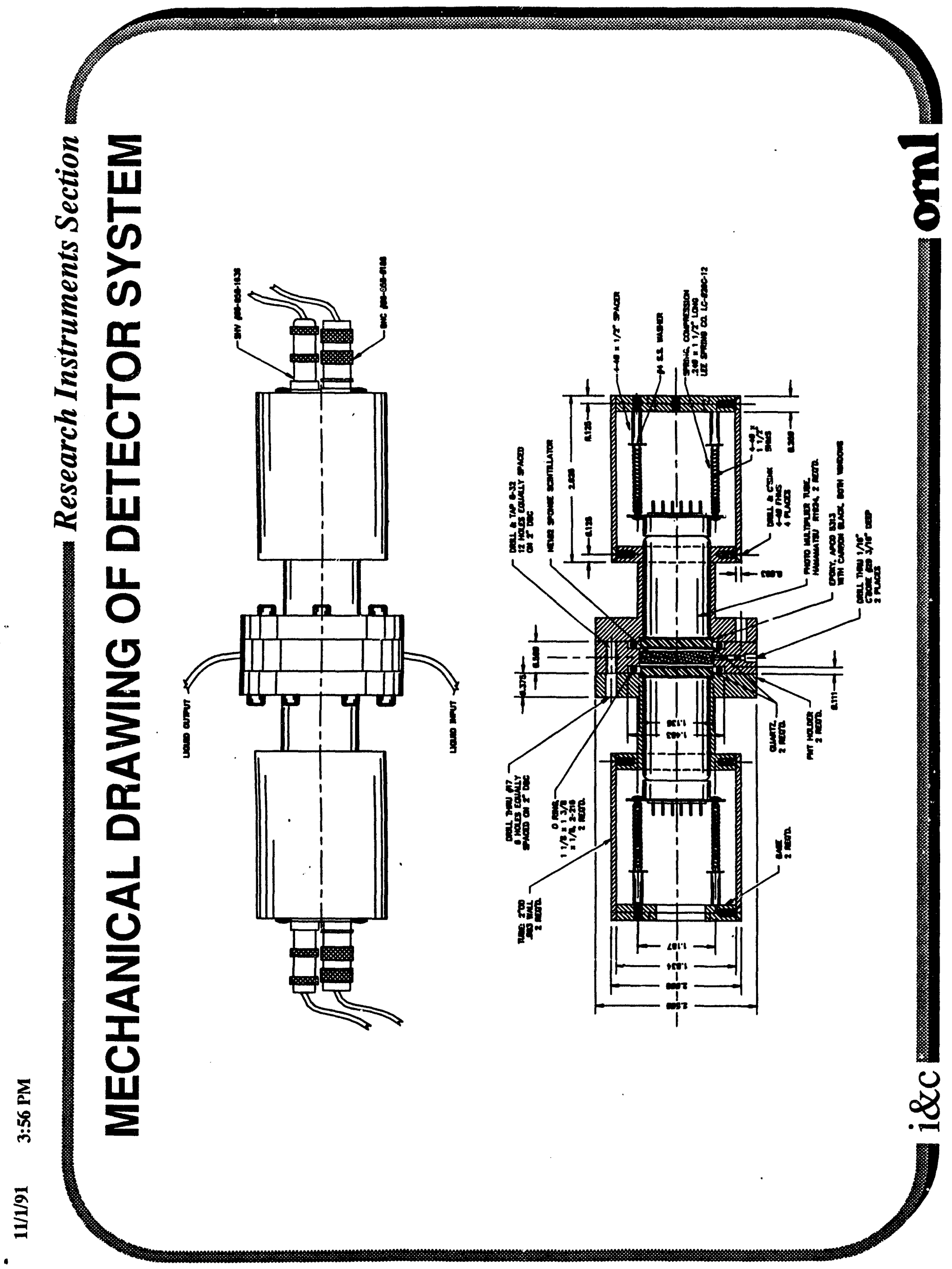




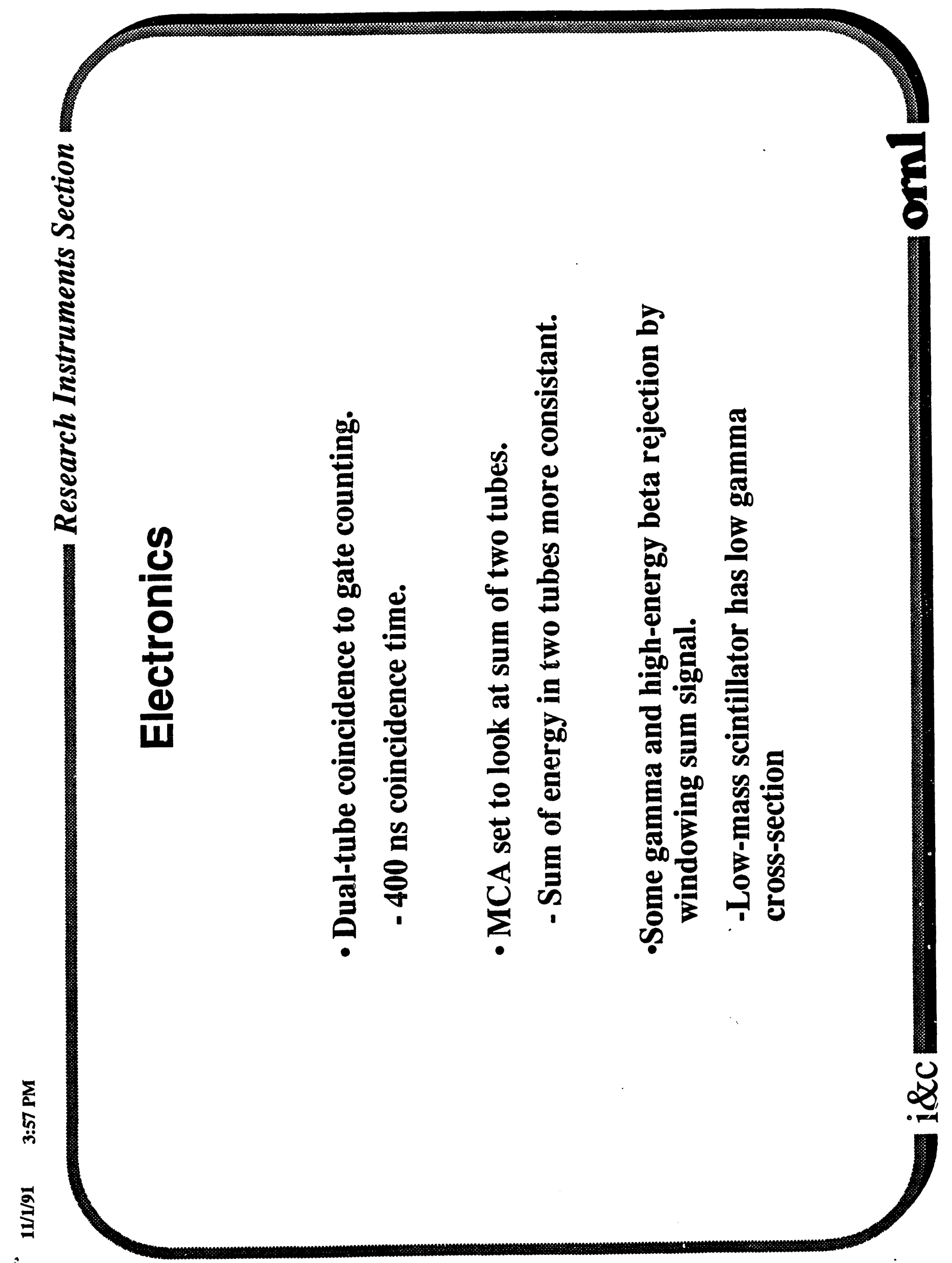




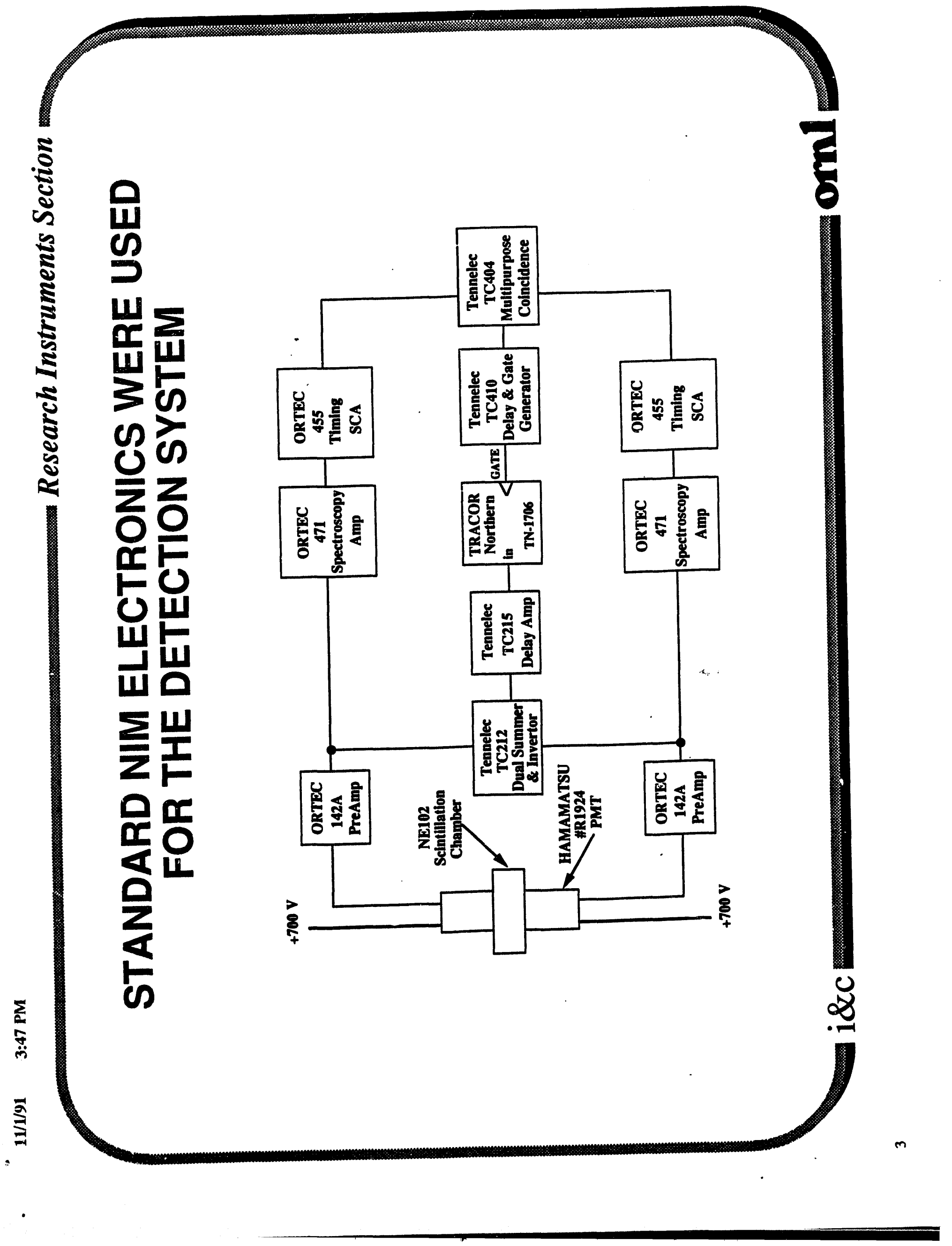




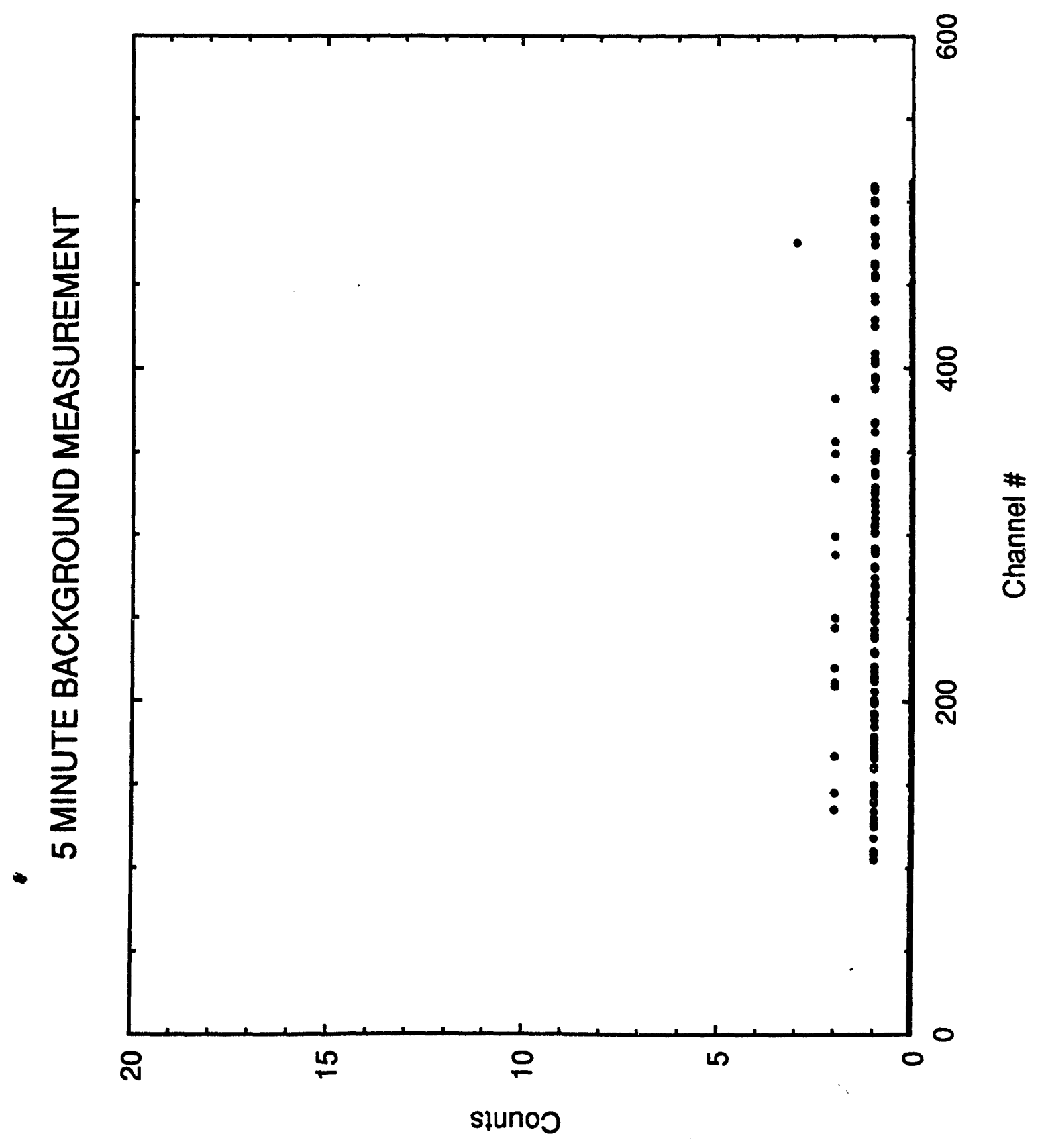




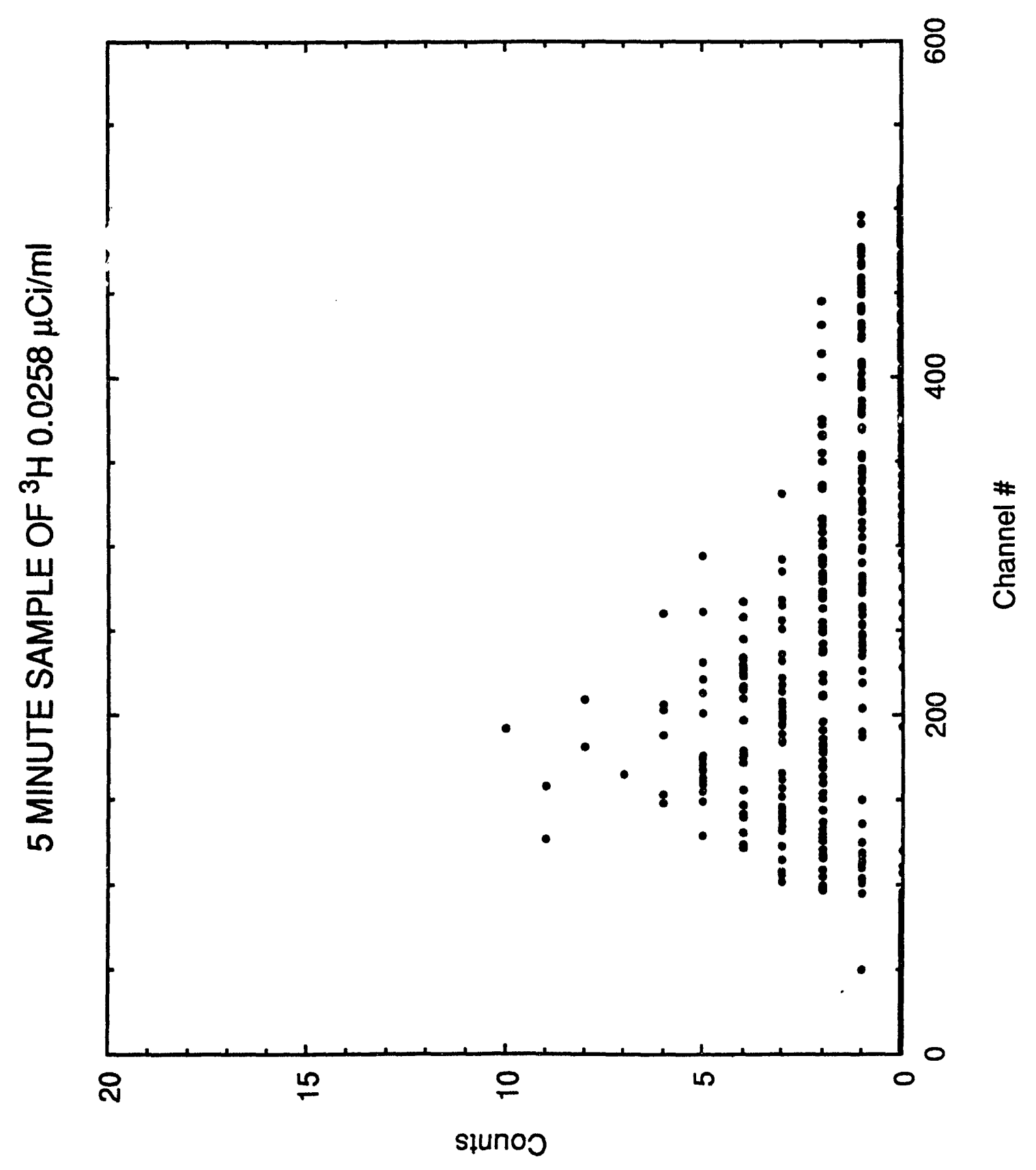




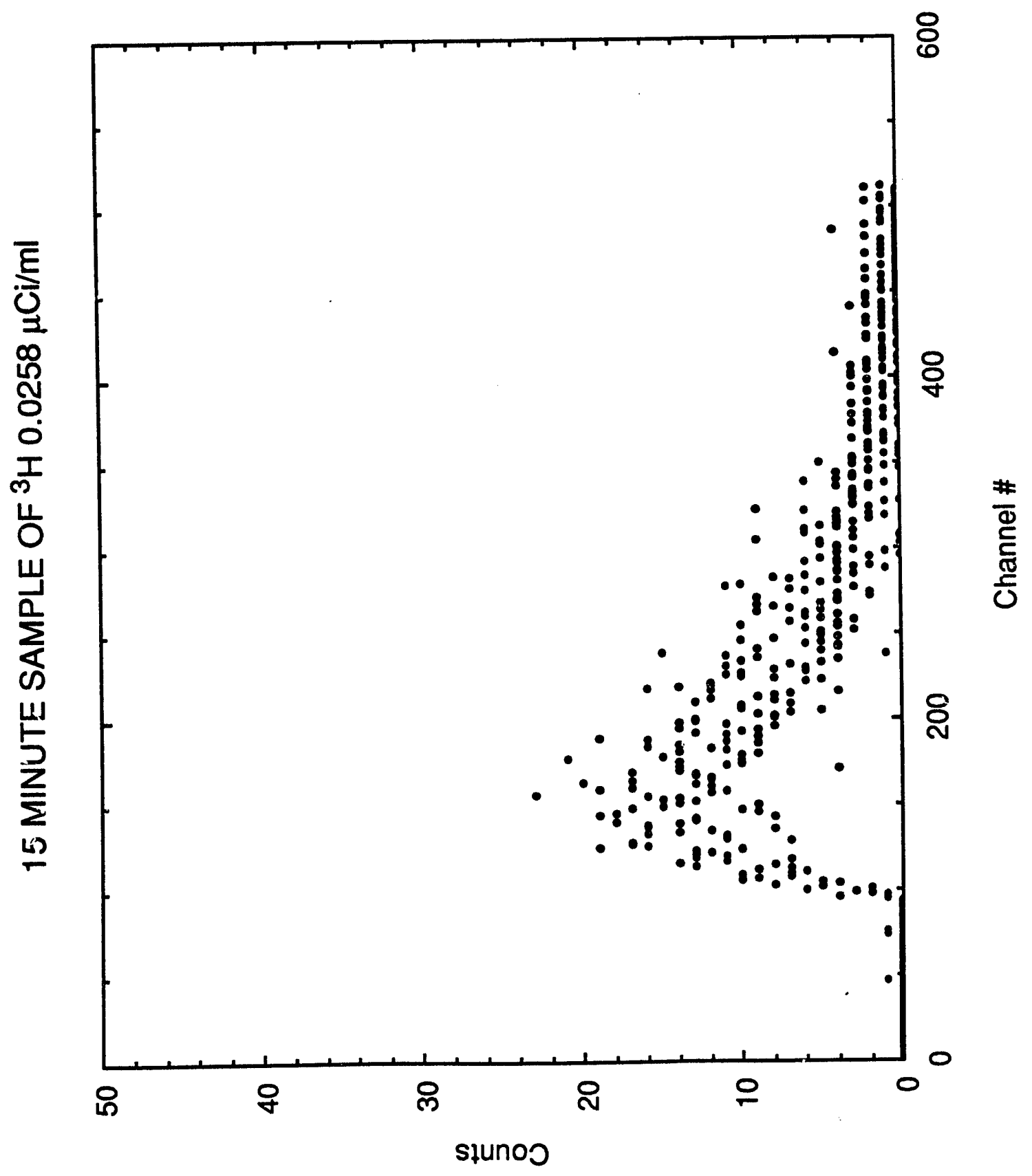




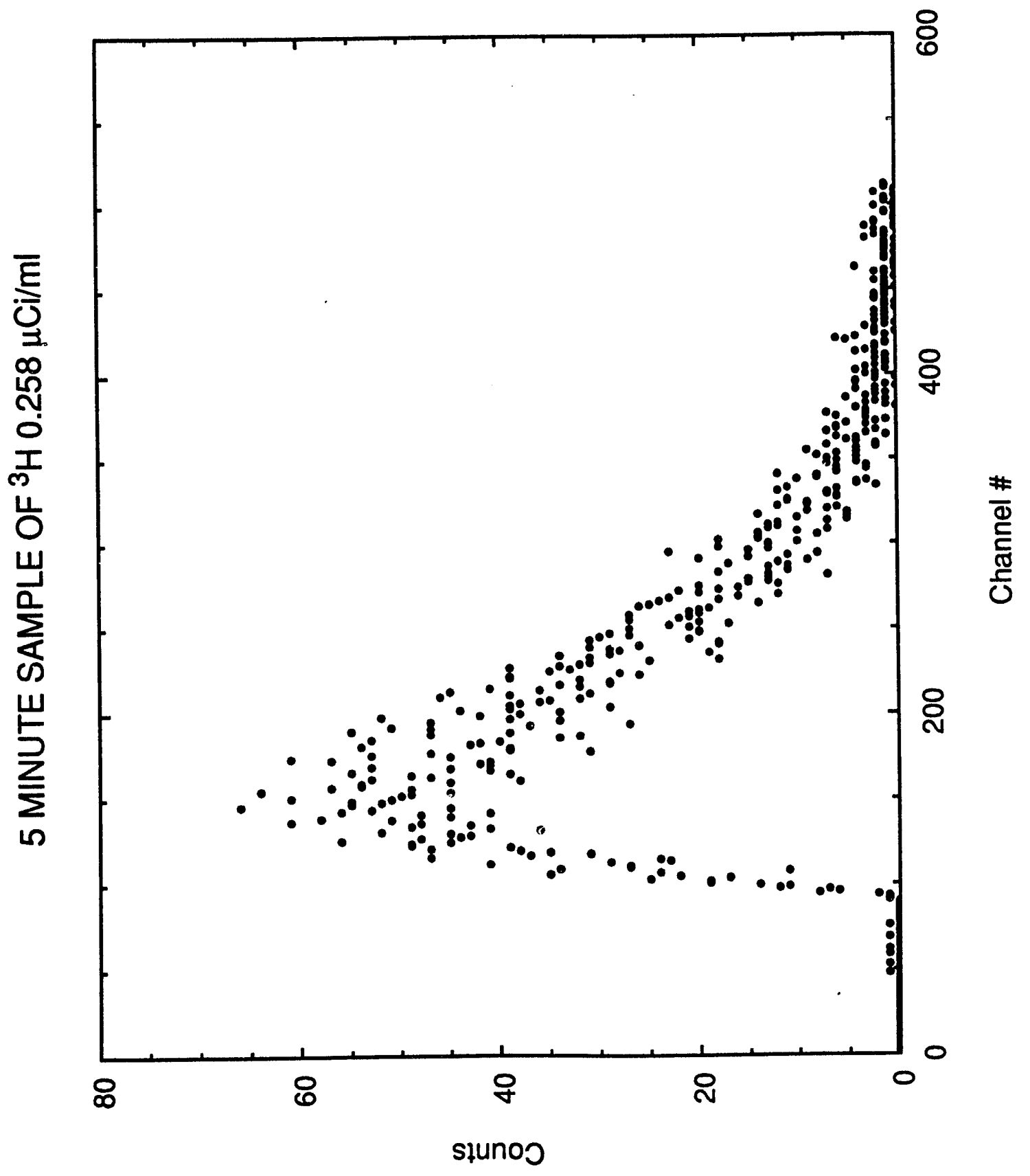




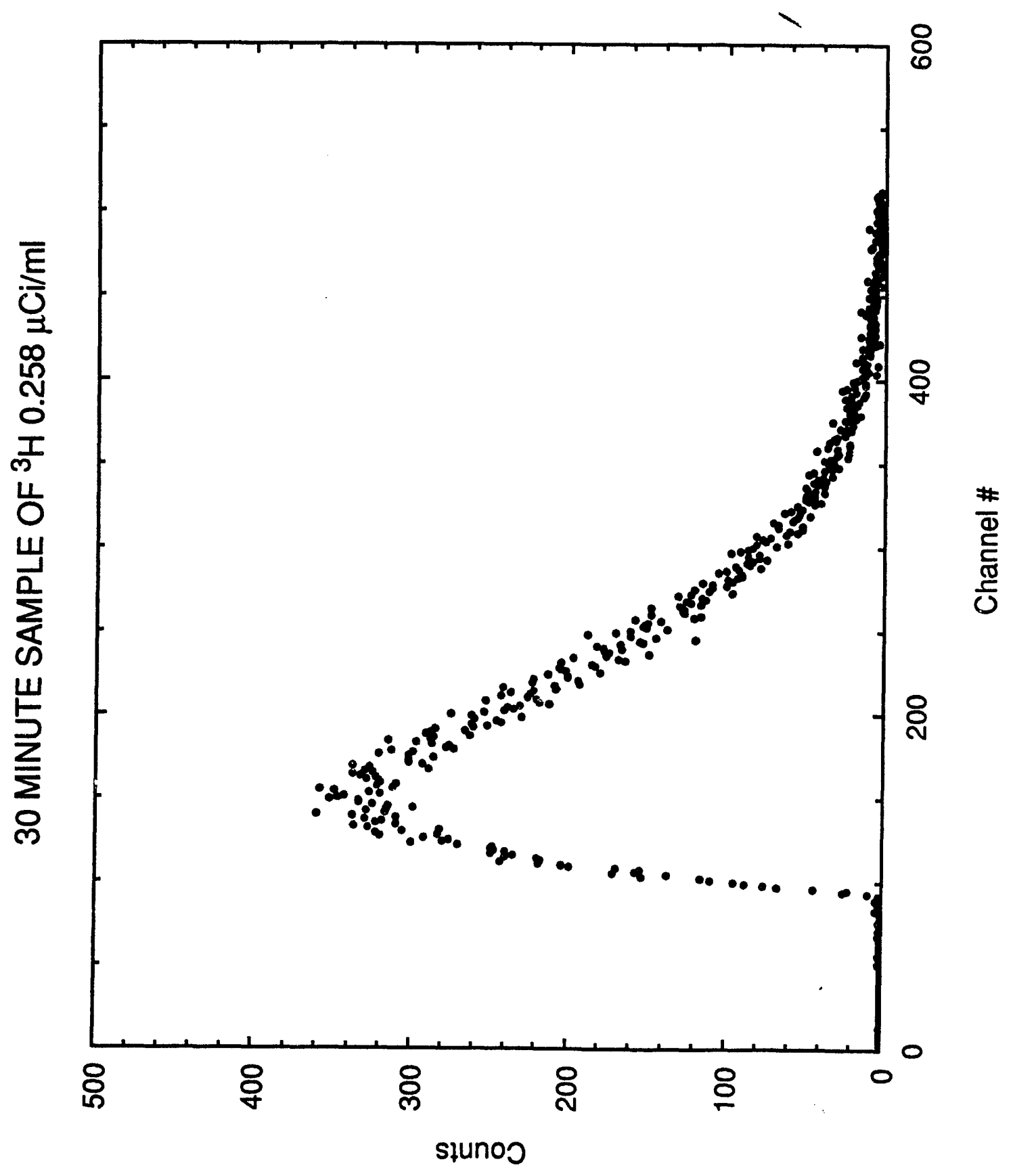




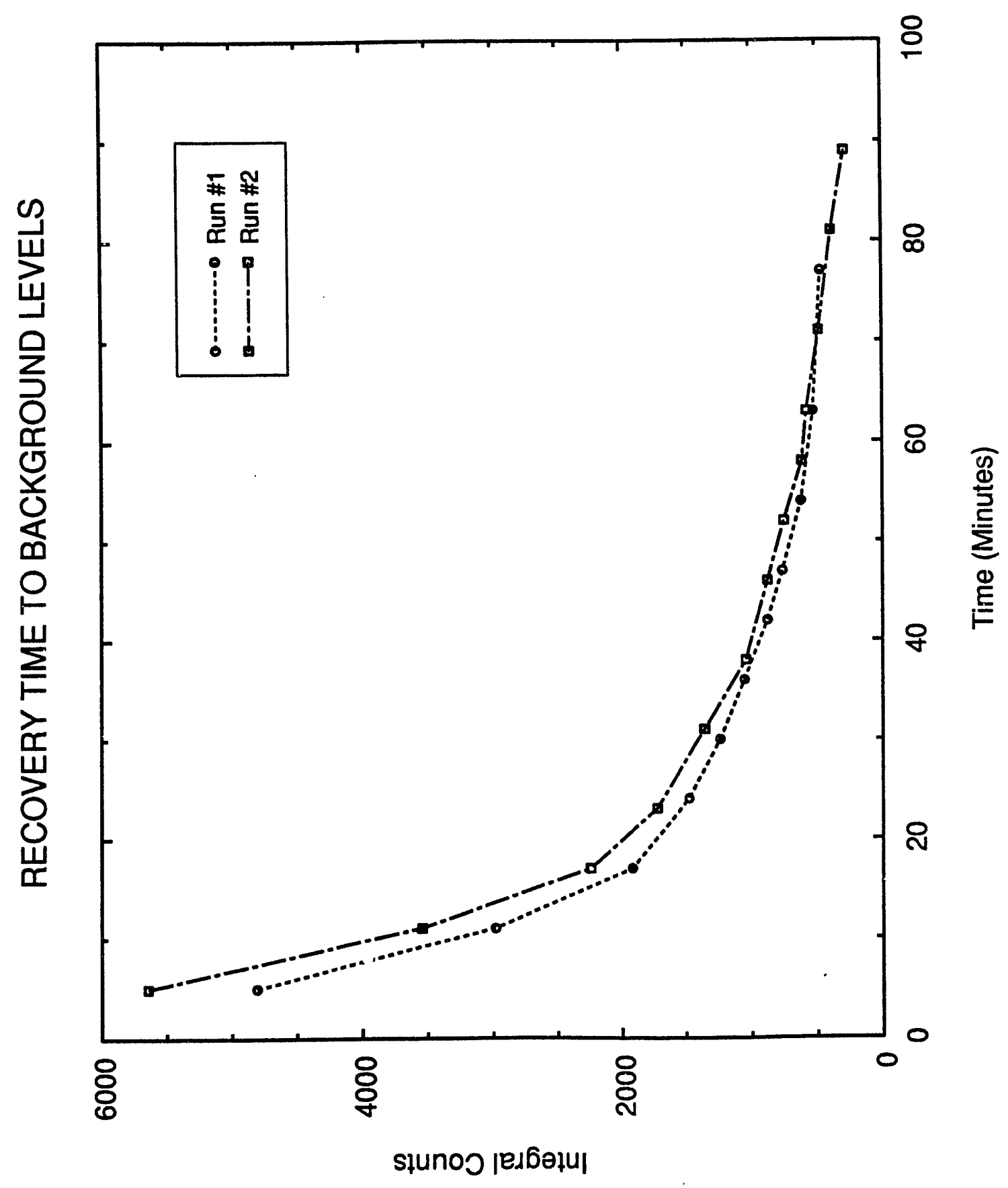



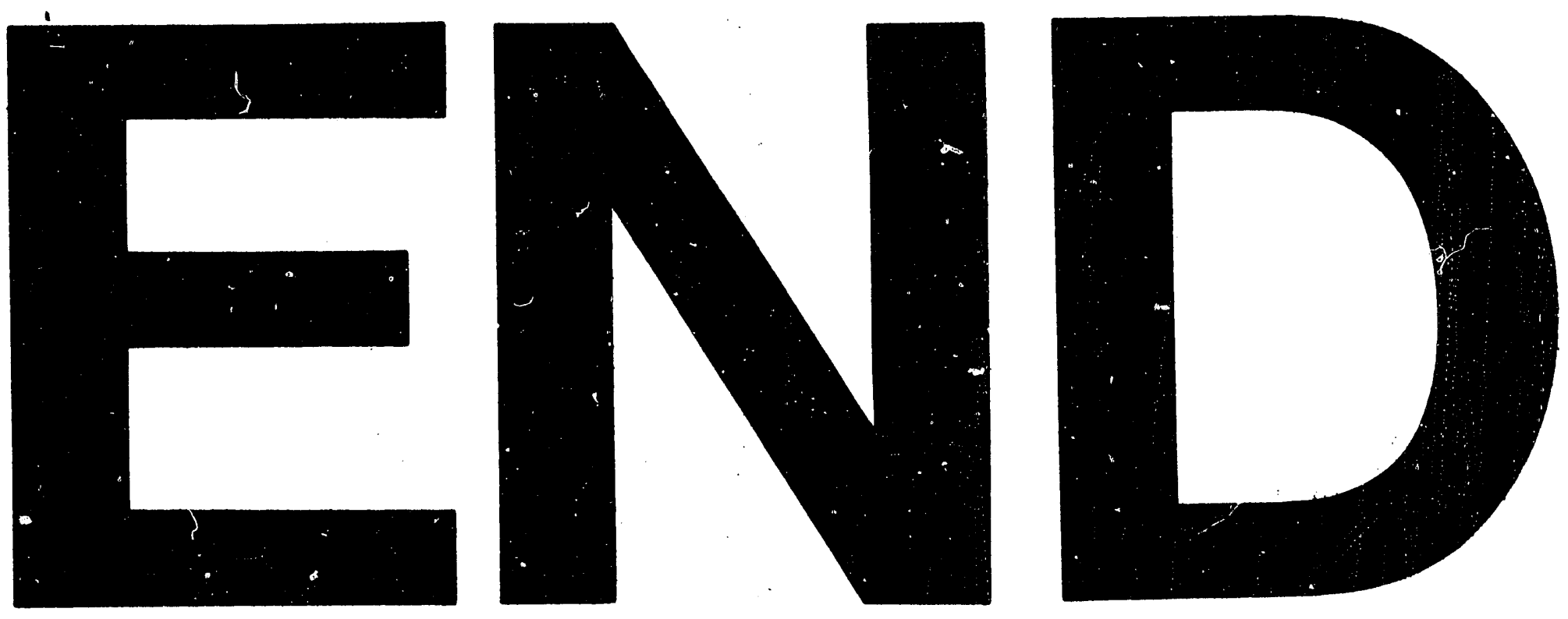

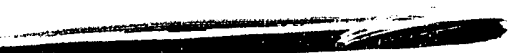

1:

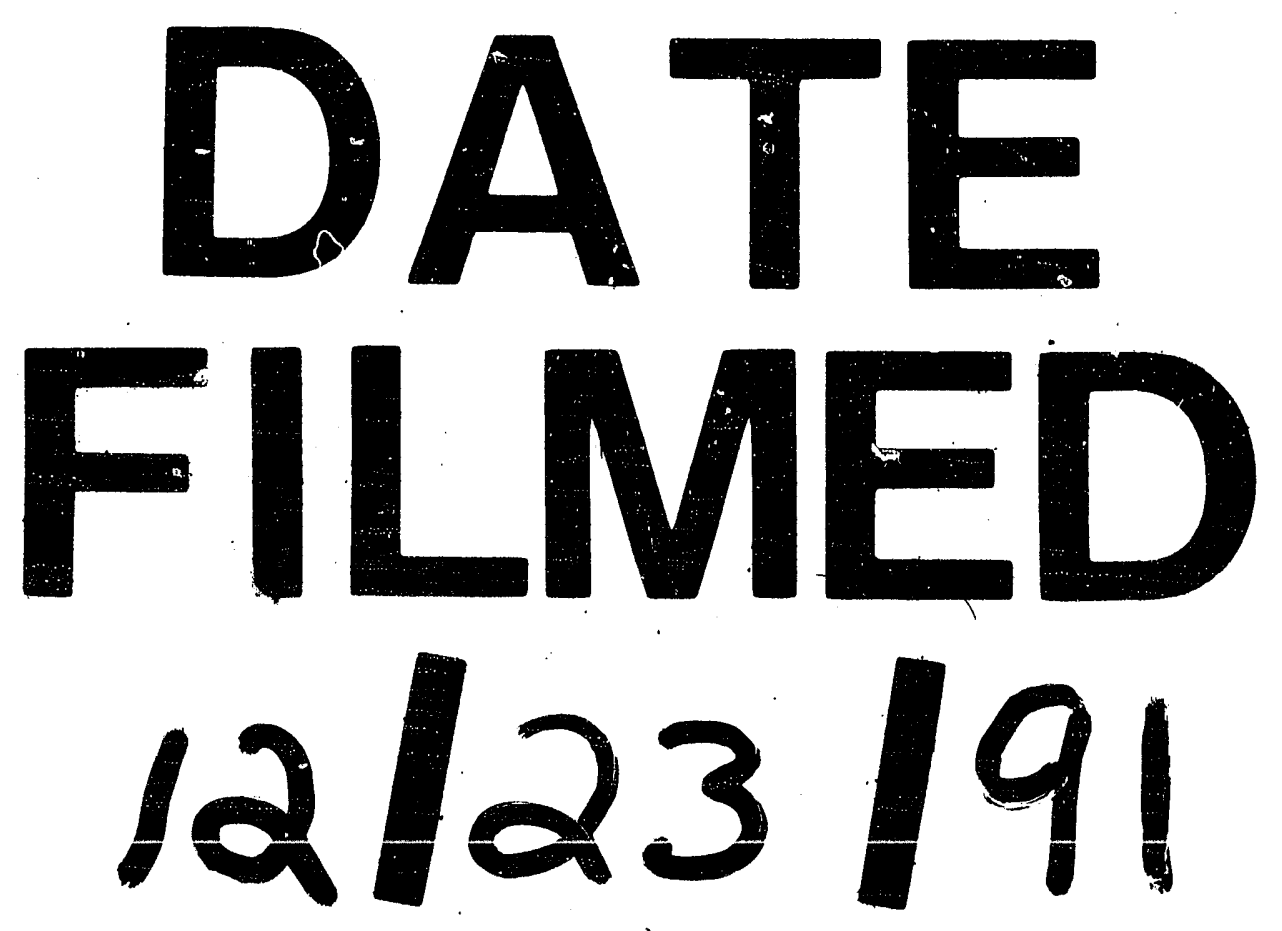

$I$ 
